\title{
Effect of Ambient Temperature on the AC Electrical Treeing Phenomena in an Epoxy/Layered Silicate Nanocomposite
}

\author{
Jae-Jun Park \\ Department of Electrical and Electronic Engineering, Joongbu University, Geumsan 312-702, Korea
}

Received July 19, 2013; Revised July 22, 2013; Accepted August 5, 2013

\begin{abstract}
Effects of ambient temperature on the ac electrical treeing and breakdown behaviors in an epoxy/layered silicate ( $1 \mathrm{wt} \%)$ were carried out in needle-plate electrode geometry. A layered silicate was exfoliated in an epoxy base resin,, using our ac electric field apparatus. To measure the treeing initiation and propagation, and the breakdown rate, constant alternating current (ac) of $10 \mathrm{kV}(60 \mathrm{~Hz})$ was applied to the specimen in a needle-plate electrode arrangement, at $30^{\circ} \mathrm{C}, 90^{\circ} \mathrm{C}$ or $130^{\circ} \mathrm{C}$ of insulating oil bath. At $30^{\circ} \mathrm{C}$, the treeing initiation time and the breakdown time in the epoxy/layered silicate ( $1 \mathrm{wt} \%$ ) system were 1.4 times higher than those of the neat epoxy resin. At $90^{\circ} \mathrm{C}$ (lower than Tg), electrical treeing was initiated in $55 \mathrm{~min}$, and propagated until $1,390 \mathrm{~min}$ at the speed of $0.35 \times 10^{-3} \mathrm{~mm} / \mathrm{min}$, which was 4.4 times higher than that at $30^{\circ} \mathrm{C}$; however, there was almost no further treeing propagation after 1,390 min. At $130^{\circ} \mathrm{C}$ (higher than Tg), electrical treeing was initiated in $44 \mathrm{~min}$, and propagated until 2,000 min at the speed of $0.96 \times 10^{-3} \mathrm{~mm} / \mathrm{min}$. Typical branch type electrical treeing was obtained from the neat epoxy and epoxy/layered silicate at $30^{\circ} \mathrm{C}$, while bush type treeing was observed out from the needle tip at $90^{\circ} \mathrm{C}$ and $130^{\circ} \mathrm{C}$.
\end{abstract}

Keywords: Electrical treeing, Epoxy nanocomposite, Layered silicate, Treeing phenomena

\section{INTRODUCTION}

Epoxy resins have good mechanical and thermal properties, as well as excellent electrical properties; thus they have been used as insulation materials in the field of heavy electric equipment, such as mold-type transformers, current transformers (CT), potential transformers (PT), metering out-fit (MOF), and gas switching gears [1-3]. In recent years, many researchers have studied nanocomposites for developing new insulation materials, because the nanocomposites have special characteristics that are suitable to be used in advanced functional applications. The recent surge of interest in high voltage insulating materials based on layered silicates and epoxy matrixes has been inspired by the realization of these nanocomposites,

${ }^{\dagger}$ Author to whom all correspondence should be addressed: E-mail: jjpark@joongbu.ac.kr

Copyright $\odot 2013$ KIEEME. All rights reserved.

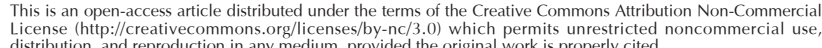
(t) which exhibit unusual ac insulation breakdown strength, and partial discharge resistance, as compared to their bulk counterparts [4-6].

Multilayered silicates treated with an organic modifier have been well known as nano-sized fillers in epoxy nanocomposites. When a multilayered silicate particle is mixed with an epoxy resin, the epoxy resins and curing agents penetrate into the interlayers of the multilayered silicate, and separate the sheetlike monolayers from each other in the epoxy matrix, forming an intercalated or exfoliated state [7-9].

To study the insulation performance of the epoxy/layered silicate nanocomposites, many works have been done by studying the electrical treeing phenomena, in order to estimate the insulation characteristics of neat epoxies or their nanocomposites, because the treeing phenomena was often referred as the most important mechanism for the deterioration of polymeric insulators (e.g. high voltage polymeric cables) [10-13]. The treeing growth mechanism is divided into three processes: (1) incubation process, (2) initiation process, and (3) propagation process. If an electrical treeing is initiated, it propagates rapidly, and 
finally the breakdown occurs. Hence, the initiation time should be delayed and the propagation rate be retarded, in order to get excellent insulation polymeric materials.

In this study, an epoxy/layered silicate nanocomposite for the insulation of heavy electric equipment was prepared by our electric field method, and the effect of ambient temperature on the electrical treeing phenomena was studied in needle-plate electrodes.

\section{EXPERIMENTS}

\subsection{Materials}

A commercial DGEBA (diglycidyl ether of bisphenol A) type epoxy resin, YD 128 (Kukdo Chem. Co.) was used. The equivalent weight was 184 190, and the viscosity was $11,500 \sim 13,500$ cps at $25^{\circ} \mathrm{C}$. The curing agent was Me-THPA (3- or 4-methyl1,2,3,6-tetrahydrophthalic anhydride), whose grade name was HN-2200 (Hitachi Chem. Co.). It is widely used in the field of electric insulation. An accelerator was BDMA (benzyl-dimethyl amine, Kukdo Chem. Co.). Cloisite ${ }^{\circledR} 10$ A (Southern Clay Products, Inc., USA) was used as a multilayered silicate, which was a natural montmorillonite organically modified with 2MBHT (dimethyl-benzyl-hydrogenated tallow quaternary ammonium), as a sort of quaternary ammonium salt. It was also dried at $110^{\circ} \mathrm{C}$ for $24 \mathrm{~h}$ in vacuum oven, and stored in desiccator, before use.

\subsection{Specimen preparation for ac treeing test}

To prepare epoxy/layered silicate nanocomposite, DGEBA (100 g) and Cloisite $10 \mathrm{~A}$ (1.83 g) were mixed with ultrasonic homogenizer $(20 \mathrm{kHz})$ for $30 \mathrm{~min}$, and then put into an ac electric field apparatus, as shown in our previous paper [6]. The ac electric field was generated by a high voltage (HV) generator in the following conditions: (1) inter-electrode distance: $50 \mathrm{~mm}$, (2) application voltage: $11 \mathrm{kV}$, (3) frequency: $1 \mathrm{kHz}$, and (4) application time: 60 min. During the ac application time, epoxy resin penetrated into the interlayer, causing the layered silicate swell. Then, the mixture was mixed with THPA $(80 \mathrm{~g})$ and BDMA $(0.9 \mathrm{~g})$. The weight percent of nano-silicate in the epoxy nanocomposite was $1.0 \mathrm{wt} \%$.

The mixture was poured into a mould having a cavity of $15 \times 15$ $\mathrm{mm}^{2}$ with $30 \mathrm{~mm}$ height, in which a needle electrode was arranged beforehand, to make the distance of needle-plate electrodes be $4.2 \mathrm{~mm}$, as shown in Figure 1. Then it was cured at $120^{\circ} \mathrm{C}$ for $2 \mathrm{hr}$, and post-cured at $150^{\circ} \mathrm{C}$ for $2 \mathrm{hr}$, and then it was cooled slowly at a rate of $-0.5{ }^{\circ} \mathrm{C} / \mathrm{min}$ until room temperature, to avoid internal stress. Finally, the opposite side of the needle electrode in the epoxy specimen was coated with theconductive silver paste. The specimen shape was as shown in Fig. 1.

\subsection{AC treeing test}

To measure the treeing initiation and propagation, and the breakdown rate, constant alternating current (ac) of $10 \mathrm{kV}(60$ $\mathrm{Hz}$ ) was applied to the specimen, in a needle-plate electrode arrangement in insulating oil bath. To study the effect of ambient temperature, the insulating oil temperature was heated at $30^{\circ} \mathrm{C}$ $90^{\circ} \mathrm{C}$ or $130^{\circ} \mathrm{C}$. Then, the specimen was inserted into the insulating oil, and maintained sufficiently for $2 \mathrm{hr}$, until the temperature of the needle tip area reached each testing temperature. High voltage (HV) was then applied by ac Endurance Voltage Tester (Haefely, Germany) at a rising speed of $1 \mathrm{kV} / \mathrm{s}$ until $10 \mathrm{kV}$, and kept the test voltage, until electrical breakdown took place. The

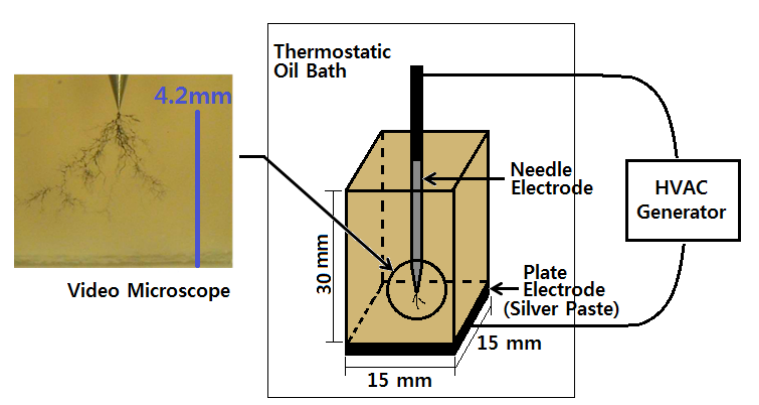

Fig. 1. Arrangement of the needle-plate electrode in a specimen.

treeing morphology was monitored by a video microscope system (ICS-305B, SOMETECH Inc.), and the treeing images were collected every $1 \mathrm{~min}$.

\section{RESULTS AND DISCUSSION}

Our previous work [6] showed that an epoxy/layered silicate nanocomposite in the exfoliated state was formed, which meant the peeled monolayers were well dispersed in the epoxy matrix. The exfoliated state was confirmed, and observed by WAXD (wide-angle X-ray diffraction) analysis and TEM (transmission electron microscopy). Therefore, the well-dispersed monolayers would act as barriers to treeing propagation.

In order to study the barrier effect on the treeing phenomena, treeing growth rate curves of the neat epoxy and the epoxy/ layered silicate (1 wt\%) system were compared, as shown in Fig. 2. When $10 \mathrm{kV}$ was applied to the specimen in needle-plate electrode arrangement, the electrical field at the needle tip, $\mathrm{E}_{\text {tip }}$ was calculated from Mason's formula [14], as follows:

$$
E_{t i p}=2 V /(r \cdot \ln (1+4 x / r))
$$

where, $\mathrm{r}$ is the needle tip radius, $5 \mu \mathrm{m}, \mathrm{V}$ is the applied voltage, 10 $\mathrm{kV}$, and $\mathrm{x}$ is the needle-plate distance, $4.2 \mathrm{~mm}$. Therefore, Etip = $492.6 \mathrm{kV} / \mathrm{mm}$.

In the neat epoxy system, electrical treeing was initiated in $10 \mathrm{~min}$, and propagated rapidly at the speed of $1.14 \times 10^{-3} \mathrm{~mm} /$ min, and finally, breakdown took place in 3,675 min, after constantly applying $10 \mathrm{kV} / 4.2 \mathrm{~mm}$. Meanwhile, in the epoxy/layered silicate system, the treeing initiation time in needle-plate electrode geometry was $30 \mathrm{~min}$, which was 3 times higher, and the breakdown time was 5,235 min, which was 1.4 times higher than those of the neat epoxy resin. The average propagation rate was $0.81 \times 10^{-3} \mathrm{~mm} / \mathrm{min}$, which was 1.4 times slower. This implied that the well-dispersed monolayers might act as barriers to the treeing propagation.

The morphology of electrical treeing for the neat epoxy and epoxy/layered silicate system is compared in Figs. 3 and 4. Typical behaviors of branch type electrical treeing were obtained from the morphology observation in Fig. 3. That is to say, charges injected and extracted at the needle tip initiated small electrical treeing from the needle tip, as clearly shown in Fig. $3(a)$, and then charges were injected and extracted at the newly generated conductive treeing tip, which had been carbonized, so that several branches appeared (Fig. 3(b)). They grew rapidly, became fatter and darker, with many new branches (Fig. 3 (c)), and finally the penetration breakdown took place almost directly from the needle tip to the silver electrode plate (Fig. $3(d)$ ). 


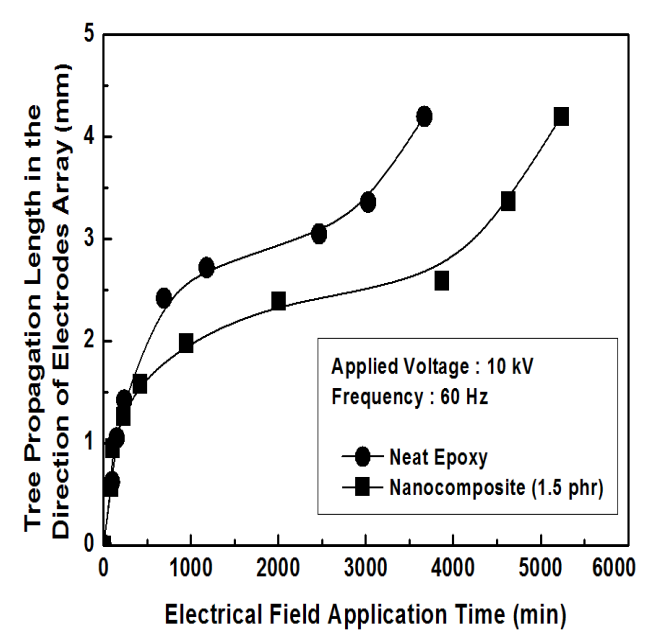

Fig. 2. Treeing growth rate in the neat epoxy resin and the epoxy/layered silicate ( $1 \mathrm{wt} \%)$ system, tested in the constant electric field of 10 $\mathrm{kV} / 4.2 \mathrm{~mm}(60 \mathrm{~Hz})$ at $30^{\circ} \mathrm{C}$.
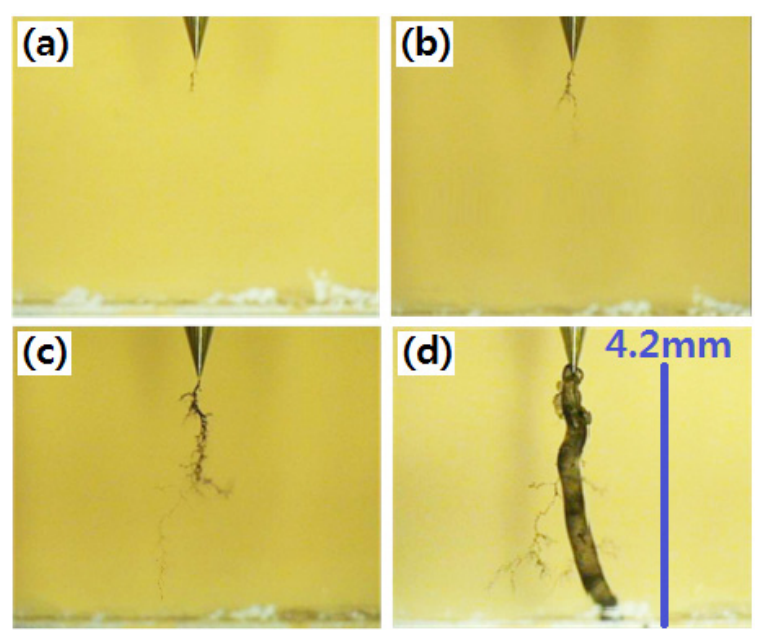

Fig. 3. Morphology of electrical treeing for the neat epoxy tested in the constant electric field of $10 \mathrm{kV} / 4.2 \mathrm{~mm}(60 \mathrm{~Hz})$ at $30^{\circ} \mathrm{C}$ for (a) 30 min, (b) $420 \mathrm{~min}$, (c) 3,550 $\mathrm{min}$, and (d) 3,675 min.

As expected, the silicate monolayers caused a barrier effect, as shown in Fig. 4. That is to say, the silicate monomers blocked the treeing growth, so that the treeing should develop a new root to propagate. It was a time-consuming process. Therefore, many branches were generated (Fig. 4(b)), and each branch also formed many new secondary branches (Fig. 4(c)), and finally the penetration breakdown trace went around from the needle tip to the silver electrode plate (Fig. 4(d)).

Figure 5 shows the effect of ambient temperature on the treeing growth rate in the epoxy/layered silicate (1 wt\%) nanocomposite. In particular, to study the glass transition temperature (Tg) of the epoxy nanocomposite, the ambient temperature was (•) $30^{\circ} \mathrm{C},(-) 90^{\circ} \mathrm{C}$ or $(\Delta) 130^{\circ} \mathrm{C}$, in which the $\mathrm{Tg}$ of epoxy nanocomposite was $125^{\circ} \mathrm{C}$.

At $90^{\circ} \mathrm{C}$ (lower than $\mathrm{Tg}$ ), electrical treeing was initiated in 55 min, and propagated until $1,390 \mathrm{~min}$ at the speed of $0.35 \times 10^{-3}$ $\mathrm{mm} / \mathrm{min}$, which was 4.4 times higher than that at $30^{\circ} \mathrm{C}$; however, there was almost no further treeing propagation after 1,390 min Therefore, the test was stopped. The incommensurable result may have been owing to the lower velocity at higher temperature in a conductive pathway. At higher temperature, the carbon at-

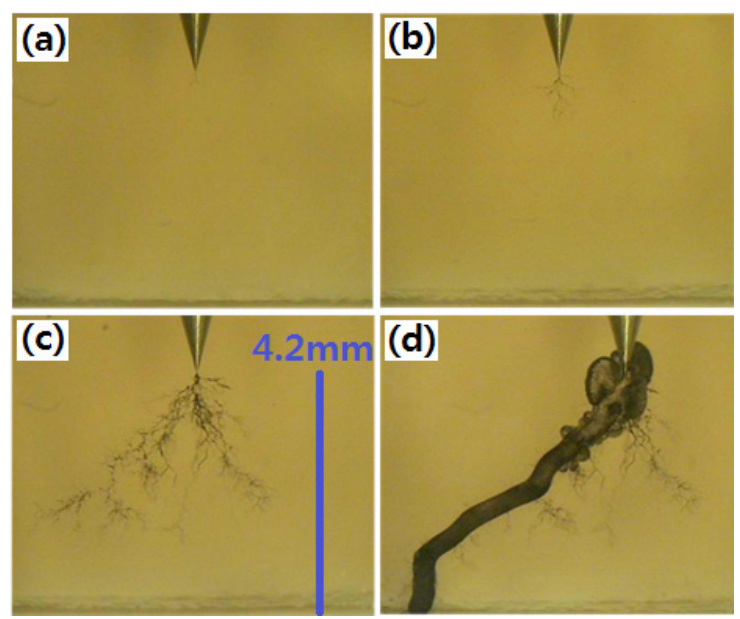

Fig. 4. Morphology of electrical treeing for the epoxy/layered silicate (1 wt\%) nanocomposite tested in the constant electric field of $10 \mathrm{kV} / 4.2$ $\mathrm{mm}\left(60 \mathrm{~Hz}\right.$ ) at $30^{\circ} \mathrm{C}$ for (a) $30 \mathrm{~min}$, (b) $450 \mathrm{~min}$, (c) 4,120 $\mathrm{min}$, and (d) $5,235 \mathrm{~min}$.

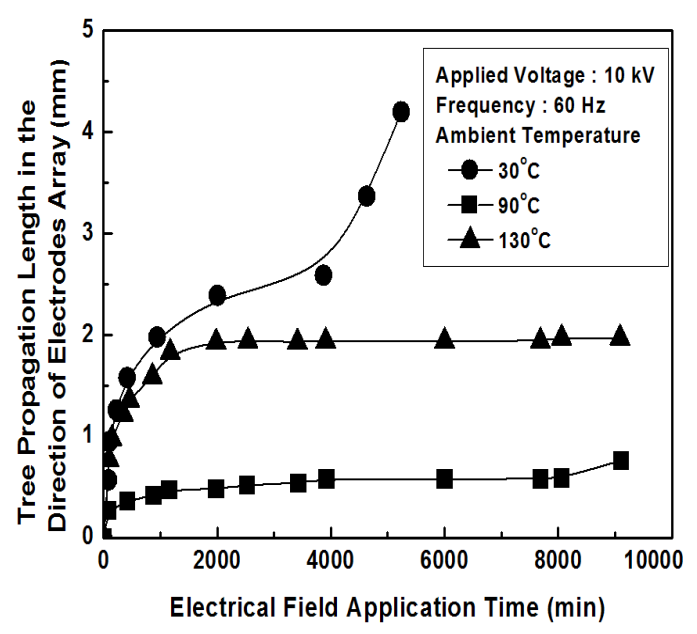

Fig. 5. Treeing growth rate in the epoxy/layered silicate (1 wt\%) nanocomposite tested in the constant $10 \mathrm{kV} / 4.2 \mathrm{~mm}(60 \mathrm{~Hz})$ at various ambient temperature. (•) $30^{\circ} \mathrm{C}$ (room temperature), (•) $90^{\circ} \mathrm{C}$ (lower than $\mathrm{Tg}$ ), and ( $\mathbf{\Delta}) 130^{\circ} \mathrm{C}$ (higher than $\mathrm{Tg}$ ).

oms in the electron pathway were more vigorously vibrated, so that the electrical resistance increased [15]. Therefore the electron momentum power to the polymer chains of the insulating material decreased.

At $130^{\circ} \mathrm{C}$ (higher than $\mathrm{Tg}$ ), electrical treeing was initiated in $44 \mathrm{~min}$, and propagated until 2,000 $\mathrm{min}$ at the speed of $0.96 \times 10^{-}$ ${ }^{3} \mathrm{~mm} / \mathrm{min}$, which was 1.3 times higher than that at $30^{\circ} \mathrm{C}$, and 2.7 times lower than that at $90^{\circ} \mathrm{C}$; however there was almost no further treeing propagation after 2,000 $\mathrm{min}$. Therefore, the test was also stopped. The propagation rate was lower than at $30^{\circ} \mathrm{C}$; however, higher than at $90^{\circ} \mathrm{C}$. This was because the epoxy chains were more easily movable, so that electrons easily transferred [16].

Bush type tree phenomena were observed out from the needle tip at $90^{\circ} \mathrm{C}$ and $130^{\circ} \mathrm{C}$, respectively, as displayed in Fig. 6 . This might be because the momentum power of the injected electrons couldn't pass through the silicate monolayers and polymer chains, so they should develop a new root, to avoid the silicate 


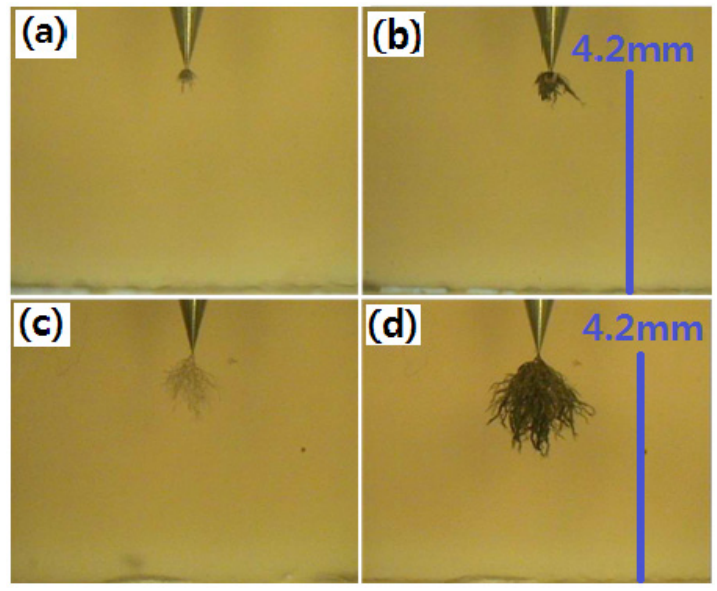

Fig. 6. Morphology of electrical treeing for the epoxy/layered silicate (1 wt\%) nanocomposite tested in the constant electric field of $10 \mathrm{kV} / 4.2$ $\mathrm{mm}(60 \mathrm{~Hz})$ at $90^{\circ} \mathrm{C}$ for (a) $1,980 \mathrm{~min}$, and (b) $10,590 \mathrm{~min}$ (7.3 days), and at $130^{\circ} \mathrm{C}$ for (c) $390 \mathrm{~min}$, and (d) $11,790 \mathrm{~min}$ (8.2 days).

monolayers and strong polymer chains.

\section{CONCLUSIONS}

Effects of ambient temperature on the ac electrical treeing and breakdown behaviors in an epoxy/layered silicate (1 wt\%) were carried out in needle-plate electrode geometry. In the neat epoxy system at $30^{\circ} \mathrm{C}$, electrical treeing was initiated in 10 $\mathrm{min}$, and propagated rapidly at the speed of $1.14 \times 10^{-3} \mathrm{~mm} / \mathrm{min}$, and finally, breakdown took place in 3,675 min. Meanwhile, in the epoxy/layered silicate system at $30^{\circ} \mathrm{C}$, the treeing initiation time was $30 \mathrm{~min}$, and the breakdown time was 5,235 min, which was 1.4 times higher than those of the neat epoxy resin. Typical branch type electrical treeing was obtained from the neat epoxy and epoxy/layered silicate; however the latter was more complex than the former. At $90^{\circ} \mathrm{C}$ (lower than $\mathrm{Tg}$ ), electrical treeing was initiated in $55 \mathrm{~min}$, and propagated until 1,390 $\mathrm{min}$ at the speed of $0.35 \times 10^{-3} \mathrm{~mm} / \mathrm{min}$, which was 4.4 times higher than that at $30^{\circ} \mathrm{C}$; however, there was almost no further treeing propagation after $1,390 \mathrm{~min}$. At $130^{\circ} \mathrm{C}$ (higher than $\mathrm{Tg}$ ), electrical treeing was initiated in $44 \mathrm{~min}$, and propagated until 2,000 min at the speed of $0.96 \times 10^{-3} \mathrm{~mm} / \mathrm{min}$, which was 1.3 times higher than that at $30^{\circ} \mathrm{C}$, and 2.7 times lower than that at $90^{\circ} \mathrm{C}$; however, there was almost no further treeing propagation after 2,000 min. Bush type tree phenomena were observed out from the needle tip at $90^{\circ} \mathrm{C}$, and $130^{\circ} \mathrm{C}$.

\section{ACKNOWLEDGMENT}

This work was supported by Joongbu University (2013).

\section{REFERENCES}

[1] J. Y. Lee, M. J. Shim and S. W. Kim, Polym. Eng. Sci., 39, 1993 (1999) [DOI: http://dx.doi.org/10.1002/pen.11592].

[2] Y. S. Cho, M. J. Shim and S. W. Kim, Mater. Chem. Phys., 66, 70 (2000) [DOI: http://dx.doi.org/10.1016/S0254-0584(00)002728].

[3] R. Sarathi, R. K. Sahu and P. Rajeshkumar, Mater. Sci. Eng.: A, 445, 567 (2007) [DOI: http://dx.doi.org/10.1016/ j.msea.2006.09.077].

[4] T. Tanaka, G. C. Montanari and R. Mülhaupt, IEEE Trans. Dielectr. Electr. Insul., 11, 763 (2004) [DOI: http://dx.doi. org/10.1109/ TDEI.2004.1349782].

[5] T. Imai, F. Sawa, T. Ozaki, T. Shimizu, R. Kido, M. Kozako and T. Tanaka, Intern. Sympos. Electr. Insulating Materials, Kitakyushu, Japan, pp. 239 (2005).

[6] J. J. Park and J. Y. Lee, IEEE Trans. Dielectr. Electr. Insul., 17, 1516 (2010) [DOI: http://dx.doi.org/10.1109/TDEI.2010.5595553].

[7] D. J. Suh and O. O. Park, J. Appl. Polym. Sci., 83, 2143 (2002) [DOI: http://dx.doi.org/10.1002/app.10166].

[8] L. Zhang, Y. Z. Wang, Y. Q. Wang, Y. Sui and D. S. Yu, J. Appl. Polym. Sci., 78, 1873 (2000) [DOI: http://dx.doi. org/10.1002/1097-4628(20001209)].

[9] H. L. Tyan, K. H. Wei and T. E. Hsieh, J. Polym. Sci.: Part B, 38, 2873 (2000) [DOI: http://dx.doi.org/10.1002/10990488(20001115)].

[10] T. Imai, F. Sawa, T. Yoshimitsu, T. Ozaki, and T. Shimizu, IEEE Annual Report Conference on CEIDP, p.239 (2004).

[11] T. Tanaka, IEEE Transactions on Dielectrics and Electrical Insulation, 9, 704 (2002) [DOI: 10.1109/TDEI.2002.1038658].

[12] R. Vogelsan, T. Farr, and K. Frohlich, IEEE Transactions on Dielectrics and Electrical Insulation, 13, 373 (2006) [DOI: http:// dx.doi.org/10.1109/TDEI.2006.1624282].

[13] L. A. Dissado, IEEE Transactions on Dielectrics and Electrical Insulation, 9, 483 (2002) [DOI: http://dx.doi.org/10.1109/ TDEI.2002.1024425].

[14] K. Theodosiou and I. Gialas, J. Electr. Eng., 59, 248 (2008).

[15] L. A. Pendrys, C. Zeller and F. L. Vogel, Journal of Materials Science, 15, 2103 (1980) [DOI: http://dx.doi.org/10.1007/ BF00550638].

[16] S. Singha and M. J. Thomas, IEEE Trans. Dielectr. Electr. Insul., 15, 12 (2008) [DOI: http://dx.doi.org/10.1109/TDEI.2008.4446732]. 